\title{
O ENSINO DE FILOSOFIA COMO MEDIADORA UNIVERSAL PARA EXISTENNCIA HUMANA
}

\section{Luís Carlos Pereira}

\begin{abstract}
Mestrando em Educação pela Universidade Nove de Julho (UNINOVE). Licenciando em Pedagogia pela Universidade Cruzeiro do Sul (UNICSUL). Graduado em Biblioteconomia pela Fundação Escola de Sociologia e Política de São Paulo (FESPSP) e Pós-graduação Lato Sensu em Planejamento de Sistemas de Informação pelas Faculdades Integradas Teresa Davila (FAINC). Atualmente é Bibliotecário/Documentalista do Instituto Federal de Educação, Ciência e Tecnologia de São Paulo (IFSP). E-mail: luiscarloscaue@hotmail.com
\end{abstract}

Roseli Margarete de Almeida Nanni

\begin{abstract}
Mestranda em Educação pela Universidade Nove de Julho (UNINOVE). Licenciada em Geografia pela Universidade Cruzeiro do Sul - UNICSUL, Graduada em Pedagogia pela Falc e Pós-graduação Lato Sensu em Educação Especial e Inclusiva, com ênfase em Altas Habilidades/Superdotação pela Universidade Estadual Paulista Julio de Mesquita Filho - UNESP. Integrante do GRUPEC: Grupo de Pesquisa em Educação e Complexidade, sediado na Universidade Nove de Julho UNINOVE. Atualmente é Professora de Ensino Fundamental II e Médio na Prefeitura Municipal de São Paulo, bem como, na Rede Pública de Ensino do Estado de São Paulo. E-mail: roseli_m_almeida@yahoo.com.br
\end{abstract}

Doutoranda pela Universidade Nove de Julho - UNINOVE; Mestre em Educação titulada pela Universidade Metodista de São Paulo; Graduada em PEDAGOGIA pela Faculdade de São Bernardo do Campo (2000) e Pós graduação Lato Sensu em Violência Doméstica pela Universidade de São Paulo - USP - (2003). Atualmente é professora do Ensino Fundamental na prefeitura Municipal de Santo André; integrante do GRUPEC: Grupo de Pesquisa em Educação e Complexidade, sediado na Universidade Nove de Julho - UNINOVE. Tem experiência na área de Educação, com ênfase em Alfabetização. E-mail: matilde.antonelli@ig.com.br

\section{RESUMO}

Este artigo tem como objetivo demonstrar a importância do ensino da Filosofia da Educação como mediadora universal da existência humana. Por meio da filosofia, oferecer ao educando formação política, ética e estética, em que os princípios valorativos da sociedade devem ser integrados na sua formação de 
modo que se constituam cidadãos com sensibilidade mais humanitária. Assim, é necessário trabalhar as reflexões filosóficas, debates, diálogos, ensaios, música, dentre outros, para buscar essa formação das humanidades, tornando os cidadãos mais conscientes das suas funcões sociais e ao mesmo tempo contribuir para que essa formação humanística não fique restrita a índices de poder econômico, em que aos menos favorecidos chegue apenas a formação tecnicista com práticas e regras pré-estabelecidas pelo setor industrial. Embora, os sistemas educacionais a grosso modo sejam planejados para atender a fins capitalistas, o professor de filosofia poderá encontrar brechas dentro dos sistemas educacionais e contribuir, significativamente, para a formação do educando, independentemente do poder econômico do estudante. Pois, a formação humana alimenta a inteligência geral, promove a autonomia, ajuda a refletir acerca do mundo e da vida, desenvolve habilidades necessárias para o convívio social com práticas de cidadania para o devir, contribuindo na formação ética do indivíduo e na apropriação dos bens simbólicos por ele produzido. Portanto, o educador, pelos conjuntos das reflexões e ações aqui apresentadas, expressa que é possível construir subsídios para intencionalizar a prática pedagógica no ensino de filosofia para a formação valorativa do estudante, consciente com o trabalho, com o Estado e com a sociedade e pelos valores que são parte integrante do indivíduo como ser social.

PALAVRAS-CHAVE: Filosofia da Educação. Ações educativas. Educador. Educando. Existência humana.

\title{
THE TEACHING OF PHILOSOPHY AS A MEDIATOR FOR HUMAN EXISTENCE
}

\begin{abstract}
This article aims to demonstrate the importance of the teaching of philosophy of education as universal mediator of human existence. By means of philosophy, offer the learner training policy, ethics and aesthetics, in which the value principles of society must be integrated into this training so that they become citizens with humanitarian sensitivity. Thus it is necessary to work the philosophical reflections, debates, dialogues, essays, music, among others, to get that training of Humanities, making citizens more aware of their social functions and at the same time contribute to this humanistic education not be restricted to indices of economic power, in which for the less fortunate is offered just technical training with pre-established rules and practices by industrial sector. Although educational systems roughly are planned to meet the capitalist purposes, philosophy professor may find loopholes within the educational systems and contribute significantly to the formation of the learner, regardless of the economic power of the student. Yes, the human formation feeds general intelligence, promotes autonomy, helps reflect about the world and life, develops skills necessary for the practice of social citizenship for the future, contributing to the formation of ethics for individual and appropriation of symbolic goods produced by him. Therefore, the educator, by sets of reflections and actions presented here, expressed that it is possible to construct grants for contribute the pedagogical practice in teaching philosophy for training student evaluative, conscious with the work, with the State and society and the values that are an integral part of the individual as a social being.
\end{abstract}


KEYWORDS: Philosophy of Education. Educational Actions. Educator. Educating. Human Existence.

A finalidade da educação é a busca de mais vida (DEWEY, 1971 apud SEVERINO, 2012, p. 84).

\section{INTRODUÇÃO}

Falar de Filosofia da Educação em momentos de turbulências políticas, religiosas, ecônomicas e sociais, em que os valores para a vida em sociedade tem tornado-se nebulosa e difícil. Quando a distopia tem avançado significativamente por meio dos "discursos políticos, religiosos, jornalísticos", dentre outros. Parecem-nos que tem agradado parte da sociedade brasileira. Por esse motivo, falar de reflexões filosóficas não tem sido fácil, porque muitos chegam a interpretar como ideologias, o que não corresponde aos fatos. Todavia, em momentos assim, cabe àqueles que têm compromisso com a educação encontrar as brechas para construir novas ações educativas dentro desse cenário.

Ao educador, por sua vez, cabe não se convencer de práticas errôneas, mas problematizá-las, a partir das reflexões, debates, diálogos, à medida que tiver oportunidade no exercicio da práxis ${ }^{1}$ educativa. Dessa forma, contribuir para o bem maior da humanidade é oferecer subsídios para si e para as próximas gerações mediante sua internação na naturareza e ao mesmo tempo constiuindo cidadãos mais conscientes por meio da formação valorativa para o exercício de práticas sociais. É, portanto, o objetivo deste artigo é demonstrar a importância do ensino da filosofia na educação, na formação de cidadãos que perpassem os modelos tecnicistas atuais, por meio da formação política, ética e estética para a continuidade da existência humana, a partir de duas implicações.

Uma primeira implicação no contexto do trabalho do professor é refletir sobre a espécie humana e sua intervenção na natureza para se manter e se constituir de forma consciente. Onde as ações educativas ultrapassem os limites do senso comum, dos mitos e das crenças, em uma atividade reflexiva, na esfera dos processos cognitivos. "Para se reproduzir, a espécie humana depende de aprendizagem porque é, talvez, a única em que o código genético não responde pela maior parte do repertório e habilidades necessárias para sobreviver” (SEVERINO, 2012, p. 83). É no sentido de continuidade da espécie que a filosofia na educação tem importante papel para a humanidade.

\footnotetext{
${ }^{1}$ Neste artigo: a práxis educativa e ações educativas têm o mesmo significado.
} 
Uma segunda implicação é pensar a humanidade biologicamente que, conforme Cuche (2012), coloca os valores culturais como fornecedores da resposta mais satisfatória das diferenças, além dos termos biológicos, isso porque fornecem ao homem a capacidade de adaptar-se ao meio e provocar mudanças de sobrevivência. Isso é, mesmo que de maneira informal ou formal, a espécie humana subjetivamente age intencionalmente. Dessarte, por ser a única espécie que pensa e, ao mesmo tempo, pensa pelo ato de pensar, a formação deve ser norteada para a manutenção da vida de forma consciente.

Nesse sentido, a filosofia busca assegurar o devir da humanidade; é preciso repensá-la de modo que não se corra o risco de o existir humano ficar desorientado, fragmentado, limitado. Por essas razões, a filosofia na educação deve refletir os valores sociais como subsídio humano, ou seja, preparar o terreno para as futuras gerações. Essas situações futuras poderão ser problematizadas pelo professor com e seus alunos, abrindo caminho para o pensar da continuidade humana de forma orientada.

Desenvolver as leituras literárias, reflexões, debates e diálogos, mostrar que o processo educativo não está isolado do cotidiano do educando, mas está presente com todas as suas contradições e complexidades, que devem estar inseridas e levadas em consideração em todas as etapas e momentos de ensino. Isto é, filosofia nos ajudando a refletir acerca do mundo, especialmente, das relações humanas e das práticas educativas, pois, ao contribuir com a formação dos educandos, reciprocamente o educador está contribuindo com sua autoformação.

Aqui a formação do educador é entendida como um processo de aprendizado para sua própria vida e para a vida dos educandos. Nessa perspectiva, a práxis educativa do educador no exercícios de seu oficio é imprescindível, uma vez que busca construir o pensamento reflexivo por meio de suas ações no aluno. E, consequentemente, poderemos ter um mundo com justiça social e igualitária. Além disso, a manutenção dos meios democráticos como premissa de vida em sociedade.

Para Aristóteles, a premissa da vida humana "consiste em se descobrir e realizar sua finalidade no mundo, o que se dá somente pela prática das virtudes”. Em Severino (2012, p. 85), encontra-se "a primeira finalidade da vida é a manutenção e a reprodução de si mesma." São diversos os conceitos encontrados na literatura a respeito das finalidades da vida humana. Mas aqui está no significado do existir, que recai sobre o prosseguimento da vida. Nesse sentido, a filosofia da educação é primordial para continuidade da vida de forma consciente. E, isso se 
dará por meio da educação voltada para os princípios valorativos da humanidade.

Educar, claro, também assegura a formação para o trabalho, mas ela não poderá desprezar o ensinamento para manutenção da vida, ou seja, ela deve perpassar o mundo do trabalho. Por isso, a importância de trazer para a formação as reflexões filosóficas, para que os estudantes compreendam que seu aprendizado vai além das técnicas de suas atividades profissionais no mundo capitalista. Destarte, a importância do trabalho ultrapassa valores monetários, embora justo para a manutenção da vida pessoal e familiar.

Pensar a educação, além das práticas tenicistas poder-se-ia, talvez, evitar a bárbarie, a distopia, ou pelo menos amenizá-las no atual cenário político, em que os discursos políticos "pedagógicos" são voltados para adequar a educação às exigências da sociedade industrial, colocando-a em iminente perigo. Severino (2012, p. 83): "Em cada etapa de sua História, a humanidade precisa refazer-se; não assegura seu devir histórico caso não se reaprenda continuamente". Portanto, as reflexões fillosóficas destacam-se na compreensão desse cenário, ajudam a se refazer para atenuar as angústias diante da devassa. Para isso, as ações educativas não poderão ser esporádicas, mas permanentes, na busca de atitudes favoráveis para efetiva inovação das práticas capazes de despetar nos educandos o interesse pela formação humanística. Ressalta-se, sempre, a importância de se considerar o aluno como sujeito histórico e participante da vida na sociedade.

É inegável que a sociedade precisa de técnicos, evidentemente, competentes, mas espera-se que eles recebam em sua formação esclarecimento das relações humanas para o saber social e o desenvolvimento científico e humanístico. Dessa forma, ganha o próprio profissional, o estado e a sociedade em geral. Vale esclarecer que a finalidade da filosofia não é criticar a formação para o mundo capitalista, mas de questioná-la e refleti-la, de modo que o educando não receba meramente práticas tecnicistas com metodologias pré-estabelecidas, porém formação cultural humanistica e científica.

Para uma formação cultural humanística, Morin (2002), que pela via filosófica do ensaio e do romance, alimenta a inteligência geral, enfrenta as grandes interrogações humanas, estimula a reflexão sobre o saber e favorece a integração pessoal dos conhecimentos. Mas essa cultura tende a se tornar um moinho que no nosso entender é restrita às elites dominantes. Por isso, nos "discursos políticos" a formação para o mundo do trabalho chega a ser vista como enriquecedora para a humanidade, mas cabe ao educador encontrar as brechas nos sistemas de ensino para uma educação valorativa dentro dos princípios que regem a sociedade nas relações 
de poder.

A filosofia da educação busca garantir aos educandos clara percepção das relações de poder na realidade histórica das sociedades.[...] Daí que o trabalho educativo deve subsidiar os estudantes para desvendar os vieses ideológicos do processo. Mediante a crítica aos sentidos falseados, a educação pode contribuir para a formação de nova consciência social nos educandos (SEVERINO, 2012, p. 89).

\section{A FORMAÇÃO POLÍTICA}

A formação política representa a socialização e democratização das relações de poder. Por isso, a educação poderá contribuir significativamente nessas relações, pois, é a escola propriamente o primeiro lugar (após o seu convívio familiar e social), onde formalmente o sujeito se insere e relaciona-se com o seu semelhante. É nesse momento que o educador poderá usar as experiências e vivências do educando capacitando-o, promovendo e transformando-o. Com a finalidade de melhoria da sua qualidade de vida, mas, vai além, para refletir mudanças nas relações sociais e de poder com ele e com o seu semelhante, valorizando a cidadania, a solidariedade, a amizade, bem como despertar a conscientização dos seus direitos como ser social.

A intervenção do educador por meio das reflexões filosóficas na formação política dos educandos no exercício da práxis educativa desenvolverá nestes habilidades sobre o mundo, para estabelecer a construção de uma sociedade mais justa, fazendo do aluno um ser transformador pelas relações sociais de poder, de modo que o conceitos de justiça social e solidariedade sejam compreendidos na escola e perpassem os muros e cheguem ao meio de convívio social do educando, como por exemplo: no trabalho e na comunidade em que vive.

Embora os sistemas educacionais, a grosso modo, tenham sua atuação fragmentada, cabe ao professor de filosofia ou a um professor polivalente encontrar meios para atuar na formação moral do indivíduo e assim prepará-los para a vida em coletividade, com senso crítico e reflexivo no exercício da cidadania dentro dos princípios democráticos. "A Filosofia da Educação atual aponta para essa atividade um papel essencial à construção da cidadania" (SEVERINO, 2012, p. 89). Essa construção não é tarefa simples, porquanto exige do educador compromisso com ele próprio, com o estado, com o educando e com a continuação da democracia.

A democracia nas palavras de Virginia Guichot apud Lúcio-Villegas (2012): "Falar de 
democracia é falar de justiça social”. É nesse sentido que o educador tem importante papel na formação do estudante, garantindo a sociabilidade e os meios de acesso aos bens simbólicos produzidos pela sociedade e por ele mesmo. Dessa forma, o ensino está sendo justo e participativo na construção social e democrática.

Portanto, observa-se periodicamente nos "discursos eleitorais brasileiros" que não há uma preocupação com políticas educacionais voltadas para a formação política, para o exercício pleno da cidadania. "Os responsáveis pelas políticas dos sistemas de educação se equivocam ao pretender que ela só cuide da habilitação técnica dos educandos e ao afirmar que não lhes cabe a formação política, de cunho crítico (SEVERINO, 2012, p. 90)". Não era de se esperar desses sistemas outra prática, porque mesmo os sistemas públicos de ensino abrem seus cursos direcionados para a indústria a fim de oferecer mão de obra regionalizada e qualificada de acordo com a predominância local. Daí surge a importância das discussões filosóficas ultrapassarem os muros acadêmicos para tentar melhorar o ensino ou, pelo menos, amenizar esse cenário pelo qual passa a educação brasileira.

\section{A FORMAÇÃO ÉTICA}

A ética e a Revolução Industrial com os avanços da ciência e a tecnologia adquiriram relevância fundamental para o progresso humano, mediante as sucessivas e contínuas inovações tecnológicas. A modernidade geralmente associada à Segunda Revolução Industrial ocorrida na segunda metade do século XIX representou o conjunto de transformações socioeconômicas iniciadas por volta de 1870, com a industrialização da França, Alemanha, Itália, Estados Unidos da América e Japão, caracterizadas especialmente pelo desenvolvimento de novas fontes de energia (como a eletricidade e petróleo), pela substituição do ferro pelo aço, pelo surgimento de novas máquinas e ferramentas e outros produtos químicos, como por exemplo: plásticos.

Por sua vez, a pós-modernidade está relacionada mais propriamente com a Terceira Revolução Industrial, que corresponde ao conjunto de transformações socioeconômicas iniciadas a partir da segunda metade do Século XX, com o surgimento de complexos industriais e empresas multinacionais e o desenvolvimento de indústrias química e eletrônica, simultaneamente com avanços da automação, da robótica, da tecnologia de informação, da engenharia genética e respectiva incorporação ao processo produtivo, que passou a depender cada vez mais de alta tecnologia e de mão de obra cada vez mais especializada. Por conta 
disso, a ética profissional passou a dominar o cenário globalizado, igualmente contextualizada em um sentido extremamente específico, aplicada apenas entre supostamente equivalentes. $\mathrm{O}$ grande problema é que a ética deveria justamente repensar posturas que fazem de alguns mais iguais que outros, refletindo sobre sua natureza generalizadora e universalizante, racionalizando as ações humanas até o limite do possível, diante da natureza emotiva e movida por sentimentos individualistas. Nesse contexto, os valores éticos não podem ser apenas individuais, têm que haver um pensamento coletivo para se manter em harmonia.

A espécie humana, para se manter em harmonia, em sociedade, depende dos referenciais que lhe são transmitidos nos primeiros anos de vida. No entanto, tem a capacidade de avaliar o certo ou errado e é capaz de agir com ética. Caso decida pela violação das leis, regras e normas que regem determinada sociedade ou grupo, sofrerá punição pelos seus atos, pois transgrediu valores imperativos e, consequentemente, responderá por isso.

Quando se pensa em ética, logo já se associa àquilo que é certo ou errado, lícito ou ilícito e este posicionamento foi construído historicamente, ao longo da evolução humana. Os valores éticos se concretizam nas ações diárias. Discutir esses valores traz à luz o agir e as nossas escolhas, questiona os costumes e tradições de culturas distintas, trata das diferenças e auxilia na construção do conhecimento, no respeito à diversidade, na compreensão e solidariedade. E, além disso, auxilia na construção do espírito crítico, colaborativo e justo. E nesse sentido, a filosofia entra no campo investigativo e questionador.

Mas quais são esses valores? No artigo Ética no ensino de filosofia: contribuição para a formação do jovem, de autoria de Lorieri, o autor conceitua diversos tipos de valores. Quanto aos valores morais "são aqueles que dizem respeito às atitudes, aos comportamentos, às maneiras de agir (Lorieri, 2010, p. 4)”. E, portanto, muitos desses valores são consagrados e de caráter universal.

Nessa perspectiva, a escola não poderá, e nem deve, ignorar os valores, mas a ela cabe buscar, cumprir, discutir e refletir, pois a filosofia ética como a investigativa na educação é compromisso da escola e por conta disso formará profissionais comprometidos com os princípios valorativos. Assim, a escola formará cidadãos participativos, conscientes com o trabalho, com o outro, com o estado e com a sociedade e, mormente, responsáveis com os valores que são partes integrantes do indivíduo como ser social.

Para o devir da existência humana, pesquisadores como Mattos e Dewey estão em consonância com Severino (2012), quando este diz: o sujeito intencionaliza suas práticas 
mediante à consciência subjetiva [...] e ao agir, o indivíduo se referencia aos conceitos e valores da vida social. Mattos, em artigo tecendo sobre a Filosofia da Educação em Dewey nos diz:

[...] a concepção do ser humano e da sociedade tem suas bases na noção mais ampla de transmissão da vida, em um ambiente social, por meio da comunicação de hábitos, crenças e valores. O caso mais específico deste processo da vida é a educação, pela qual a experiência de um indivíduo ou cultura se renovam e se modificam. Argumenta-se que um dos fatores fundamentais na educação é a necessidade de adaptação do indivíduo ao ambiente. A fim de que se possa incrementar e ampliar o sucesso de processos educativos, seja por procedimentos informais ou formais, é preciso ter em conta o tipo de experiência envolvida, e os efeitos desta experiência na adaptação do sujeito da educação ao seu ambiente (MATTOS, 2010, p. 1).

A escola e o educador (Morin, 2003) não deve ignorar o mundo dos educandos, a cultura das mídias, a cultura de massa, a luta de classes, a desintegração do tecido social ou familiar, as microssociedades que se formam nas periferias e se agravaram após as décadas de 1960-70, em que há leis de vingança, códigos de condutas, dentre outros. Esses conjuntos de valores não poderão ser desintegrados das escolas, mas poderão ser trabalhados pelos educadores na união da escola e na realidade social, daí é imprescindível a função da escola e do educador sobre a vida social e o exercício da ética nos educandos para termos indivíduos capazes de decidir entre o bem e o mal.

Chauí, em artigo publicado na Associação Nacional de Pós-Graduação em Filosofia, exemplifica uma atuação ética:

[...] suponhamos que tenha havido uma catástrofe natural e que se perderam as colheitas, acarretando fome; se for estabelecido pelo Estado que cada família receberá 20 quilos de cereais, sem que se leve em conta o tamanho da família e sem que se leve em conta que há famílias ricas, que podem importar alimentos, e famílias pobres, que não podem fazê-lo, ou que há famílias pequenas, que podem lucrar vendendo o excedente recebido, e famílias grandes para as quais a quantidade de cereais é insuficiente, a decisão é injusta ou corrupta por que deu o mesmo tratamento aos desiguais quando deveria igualar todos tratando-os diferentemente. (CHAUÍ, 2016).

E, por conseguinte, as famílias, a escola, o Estado e o educador poderão construir no educando o caráter ético, de justiça social, solidariedade e respeito pelas diferenças, pois os indivíduos devem ser tratados mediantes suas diferenças, como colocado por Chauí na citação supracitada, porque só assim, construiremos uma sociedade justa, democrática e com decisões 
éticas.

\section{A FORMAÇÃO ESTÉTICA}

A estética desperta a nossa consciência.

(MORIN, 2002, p. 148)

A estética remonta as reflexões filosóficas de Baumgarten, datado de 1750 que "estética" é a ciência que trata do conhecimento sensorial e chega à apreensão do belo e se expressa nas imagens da arte, na música, no cinema, entre outros, dando-os formas em contraposição à lógica como saber cognitivo e, por conseguinte, a estética é um elemento integrador da vida social. Porém, esses bens simbólicos nem sempre são manifestados de forma social. Que nas palavras de Severino (2012, p. 97):

Mas o nível de apropriação dos bens simbólicos é medida do índice de humanização dos educandos. É direito inalienável de toda pessoa o usufruto da educação, mediação fundamental. No cultivo da subjetividade, os critérios são a verdade (referente ao conhecimento), a autenticidade (na ação moral) e a felicidade (sentir estético).

O nível de apropriação recai sobre o índice de humanização, mas como direito inalienável aos bens simbólicos, porém, é dever da escola, por meio das ações educativas construir no educando sensibilidade e emoções para a apropriação dos bens culturais, tendo em vista que a estética é o ramo da filosofia que estuda o assunto. Portanto, buscar democratizar essa relação do indivíduo com o simbólico, uma vez que são bens produzidos pela sociedade e, logo, de interesse público. Não como luxo estético para parte da sociedade. Morin (2017) coloca a "Individualização, mercantilização, industrialização", refletindo sobre o lucro que os bens simbólicos converteram aos mercados. Isso desvirtua a finalidade que é trazer à luz a estética e suas pluralidades do sentir e do perceber.

A sensibilidade estética está estritamente ligada à inteligência emocional. Por meio da sensibilidade emotiva emerge a superação da racionalidade lógica. Pois afetividade olha a si mesmo, olhar para o mundo, analisar a complexidade das situações com o olhar do sentimento em detrimento à razão, tão presente na era digital, tecnológica. Voltar a estabelecer vínculos afetivos com as pessoas próximas. Humanizar nossas relações de convívio diário. Afinal, a educação é direito de toda pessoa. Dessarte, no cultivo da subjetividade, os critérios são a verdade (referente ao conhecimento), a autenticidade (na ação moral) e a felicidade (sentir estético). 
O Sentimento estético como universal, todavia, não o suscita de forma singular, assim como a cultura, a linguagem, a música, a natureza manifestam-se, mas em sua pluralidade "nem Pablo Picasso, nem Wassily Kandinsky teriam sido apreciados antes do século XX (MORIN, 2017 , p. 15)". Destarte, os países, as culturas locais, regionais ditam a denominação de beleza dentro de seus próprios conceitos. E, no processo de evolução, há simultaneamente a continuidade e a descontinuidade.

\section{CONSIDERAÇÕES FINAIS}

Pelas discussões apresentadas no decorrer desta reflexão sobre a educação como mediação universal da existência humana no caminho de transformar o ensino de filosofia, não apenas em adequar os educandos à sociedade, mas, a de transformar a realidade desses alunos, valorizando suas experiências, expectativas, desejos e práticas cotidianas, compreendendo a formação política, ética e estética. Compreende-se que o ensino de filosofia é tarefa para aqueles que estão convencidos da importância como mediadora universal da existência humana, em que os princípios valorativos da sociedade devem ser integrados na formação do educando. O ensino deve constituir por novas formas de compreender o mundo e exercer a docência de modo que a escola exerça a sua função na promoção de cidadãos com preparo político, ético e estético para a vida em sociedade.

Conclui-se que a Filosofia na Educação contribui com rigor mormente nos processos educativos, envolvendo formação valorativa. Contudo, cabe ao educador encontrar brechas nos sistemas de ensino para a práxis educativa de forma emancipadora para que as práticas profissionais do educando e sua intervenção plena na humanização no contexto social e histórico e, consequentemente, tornem educandos conscientes de suas ações sociais e democráticas. Nessa direção, os resultados e reflexões aqui apresentadas podem ser úteis à escola, ao educador e, sobretudo, em uma educação humana de cunho reflexivo.

\section{REFERÊNCIAS BIBLIOGRÁFICAS}

CHAUÍ, Marilena. A ética na política.

Disponível em: <

http://anpof.org/portal/index.php/en/co munidade/coluna-anpof/856-a-etica-dapolitica>. Acesso em: 16 fev. 2019.
CUCH, Denys. A noção de cultura em ciências sociais. Bauru: EDUSC, 2012.

FILOSOFANDO na praça. Disponível em:

$<$ http://filosofandonapraca.blogspot.co m/2013/03/alexander-baumgarten-e- 
estetica.html >.>. Acesso em: 25 nov. 2018.

LORIERI, Marcos Antonio. Ética no ensino de filosofia: contribuição para a formação do jovem. Revista Primus Vitam, São Paulo, v.1, n. 1, 2010.

LUCIO-VILLEGAS, Emílio. A construção da cidadania participativa através da educação. Rev. Lusófona de Educação, n. 20, 2012. Disponível em: $<$

http://www.scielo.mec.pt/scielo.php?scr $\mathrm{ipt}=$ sci_arttext\&pid=S1645-

72502012000100002>. Acesso em: 21 nov. 2018.

MATTOS, José Cláudio Morelli. Educação como adaptação: experiência segundo John Dewey. Filosofia \& educação, Campinas, v. 2, n. 2, out. 2010. Disponível em: <https://periodicos.sbu.unicamp.br/ojs/i ndex.php/rfe/article/view/8635517/331 0>. Acesso em: 18 nov. 2018.
MORIN, Edgar. A cabeça bem-feita: repensar a reforma: reformar $o$ pensamento. 8. ed. Rio de Janeiro: Bertrand Brasil, 2003. . Meus demônios. Rio de Janeiro: Bertrand Brasil, 2000.

. Sobre a estética. Rio de Janeiro, Pró-Saber, 2017.

SEVERINO, Antônio Joaquim. Educação, sujeito e história. 3. ed. São Paulo: Olho d'Água, 2012.

- Filosofia na formação profissional: por que ter valores políticos, éticos e estéticos na formação profissional é importante? São Paulo: Cartago, 2017.

PEREIRA, L.C., NANNI, R. M. A, ANTONELLI, M.M. O Ensino de Filosofia Como Mediadora Universal Para Existência Humana. Complexitas - Rev. Fil. Tem. Belém, v. 3, n. 2, p. 54-65, jul./dec. 2018. Disponível em:< http://www.periodicos.ufpa.br/index.php/complexitas/article/view/6722>. Acesso em: 05 de agosto de 2019. 